УДК 664.8:634.11

DOI 10.30679/2219-5335-2020-1-61-122-137

ПРЕДПОСЫЛКИ

ДЛЯ ВНЕДРЕНИЯ

ЦИФРОВЫХ ТЕХНОЛОГИЙ

В ПРОИЗВОДСТВО ПИЩЕВЫХ ПРОДУКТОВ НА ОСНОВЕ РАСТИТЕЛЬНОГО СЫРЬЯ

Причко Татьяна Григорьевна

д-р с.-х. наук, профессор

зав. ФНЦ «Садоводство»

Мачнева Ирина Александровна

канд. с.-х. наук

старший научный сотрудник

Дрофичева Наталья Васильевна

канд. техн. наук

старший научный сотрудник

лаборатории хранения

и переработки плодов и ягод

Федеральное государственное

бюджетное научное учреждение

«Северо-Кавказский федеральныи

научныии иентр садоводства,

виноградарства, виноделия»,

Краснодар, Россия

В статье представлен обзор современного состояния и степени внедрения цифровых технологий в производство продуктов питания из растительного сырья, позволяющих обеспечить получение продукта заданного химического состава, необходимого современному человеку в неблагоприятных экологических условиях. Компьютеризация технологического процесса инициализировала создание промышленных роботов, облегчивших ручной труд человека и обеспечивших эффективность управления персонификацией продукта питания. Адаптация роботов для перерабатывающих производств основывается на создании математического алгоритма выполнения требуемой технологической операции. В статье освещены научные направления, в которых цифровизация технологического процесса
UDC 664.8:634.11

DOI 10.30679/2219-5335-2020-1-61-122-137

\section{PREREQUISITES \\ FOR THE INTRODUCTION \\ OF DIGITAL TECHNOLOGIES \\ IN THE FOOD PRODUCTION \\ BASED ON VEGETABLE RAW MATERIALS}

Prichko Tatyana Grigorievna

Dr. Sci. Agr., Professor

Head. FNC "Gardening»"

Machneva Irina Aleksandrovna

Cand. Agr. Sci.

Senior Research Associate

Droficheva Natalia Vasilievna

Cand. Tech. Sci.

Senior Research Associate

of Laboratory of Storage

and Processing of Fruits and Berries

Federal state budgetary

Scientific institution

«North Caucasian Federal

Scientific Center of Horticulture,

Viticulture, Wine-making»,

Krasnodar, Russia

The article presents an overview of the current state and the degree of implementation of digital technologies in the food production from vegetable raw materials, allowing to provide a product of a given chemical composition required man under the unfavorable environmental conditions. The computerization of the technological process initiated the creation of industrial robots that make easy a manual human labor and ensure the effectiveness of the management of food personification. The adaptation of robots for processing industries is based on the creation of a mathematical algorithm for performing the required technological operation. The article presents the scientific areas in which the digitalization of the technological process gave 
дала мощный толчок для прорыва, в первую очередь, это аддитивные технологии и, прежде всего, 3D-печати продукта питания. Рассмотрены способы и методы пищевой полиграфии с точки зрения возможности индивидуализации рациона питания для отдельных групп населения. Обусловлены критерии технологической пригодности растительного сырья при применении цифровых технологий в производстве продукта питания.

Отмечено, что для «печатания» продукта пригодно сырьё мягкой, легко

Деформирующейся текстуры, переходящее в различной степени затвердение, устойчиво сохраняющее форму продукта.

Эффективно биологически ценное растительное сырьё, богатое содержанием природных полимерных гидроколлоидов, обеспечивающих при гомогенизации сырья мажущуюся консистенцию. Из плодовоягодного сырья к технологически пригодному для получения 3-D продукта можно отнести плоды и ягоды, отличающиеся высоким содержанием природных пищевых волокон, к которым относятся гемицеллюлоза, камеди, пектиновые вещества. Отмечено, что информатизация пищевых технологий помогла связать процесс создания продукта с математическими методами идентификации и прогнозирования качества продукта питания. Представлены решения по информатизации рецептур продукта, основанные на применении баз данных многолетних исследований химического состава плодов и ягод, связанных в системы балансовых уравнений, позволяющих проводить индивидуальную коррекцию состава продуктов питания.

Ключевые слова: ЦИФРОВЫЕ ТЕХНОЛОГИИ, ПИЩЕВЫЕ ПРОДУКТЫ, МАТЕМАТИЧЕСКОЕ МОДЕЛИРОВАНИЕ, РЕЦЕПТУРЫ, РАСТИТЕЛЬНОЕ СЫРЬЕ a powerful impetus to the breakthrough, first of all, it is additive technologies and, above all, 3D printing of food. The methods and ways of food printing from the point of view of the possibility of individualization of the diet for certain groups of the population. The technological criterions for the suitability of plant row materials in the application of digital technologies in the food production are revealed. It is noted that for the «printing» of the product is suitable the raw material of soft, easily deformable texture, passing in varying degrees of hardening, steadily preserving the shape of the product. The biologically valuable plant raw material rich in natural polymer hydrocolloids, providing homogenization of raw materials to greasing consistency is effective. From fruit and berry raw materials are technologically suitable for 3-D product the fruits and berries, characterized by a high content of natural dietary fibers, which include hemicellulose, gums and pectin substances. It is noted that the informatization of food technology has helped to link the process of creating a product with mathematical methods of identification and prediction of food quality. The solutions for the informatization of product formulations are presented, based on the use of databases of long-term studies of the chemical composition of fruits and berries associated in the system of balance equations, that allow to individual correct the composition of food.

Key words: DIGITAL TEHNOLOGIES, FOOD PRODUCTS, MATHEMATICAL MODELING OF RECIPE, VEGETABLE RAW MATERIAL

Введение. Новое столетие характеризуется высокими темпами информатизации всех сторон жизнедеятельности человека. Накопление и передача информации играют все более важную роль в развитии науки. Носи- 
Плодоводство и виноградарство Юга России № 61(1), 2020 г.

телем информации выступают различные источники, способные персонифицировано воздействовать на физиологический статус организма человека: электронные, визуальные, тактильные, вербальные импульсы [1].

Один из наиболее важных каналов информации для человека химический состав продуктов питания, существенно влияющий на формирование правильного рациона питания и являющийся основным критерием при создании необходимой сегодня индивидуальной, персонифицированной пищи.

Обсуждение. Интересы многих производителей выходят за рамки обычных процессов. Они ищут комплексное цифровое решение, которое выведет компанию на новый уровень. Персонификация продукта питания напрямую зависит от степени компьютеризации, соответственно роботизации технологического процесса.

По статистике Международной федерации робототехники в России на 10 тысяч рабочих приходится только три промышленных робота, тогда как в среднем по всему миру - 69, а в странах, лидирующих по уровню цифровизации, - более 100. Отставание наблюдается и по доле станков с числовым программным управлением: в Японии она составляет более 90 $\%$, в Германии и США - более 70 \%, в Китае - около 30 \%, а в России в 2016 г. было лишь 10 \% с прогнозом роста до 33 \% к 2020 году [2].

Принцип адаптации промышленных роботов для перерабатывающих производств заключен в использовании готовой платформы - стандартного промышленного робота, к которой составляется программа и алгоритм выполнения требуемой технологической операции, разрабатывается исполнительный рабочий орган с учётом специфики продукта [3].

Последовательность процессов производства продуктов питания из растительного сырья можно разделить на два этапа: первичная - обработка пищевого сырья и вторичная - переработка сырья. Сырье сильно раз- 
Плодоводство и виноградарство Юга России № 61(1), 2020 г.

личается по размеру, весу и форме, что затрудняет действия роботов. Так, для сортировки были изобретены чувствительные и мягкие захваты. Фирма SoftRobotics на одной из специализированных выставок представила гибкий захват, который может работать даже с «нежными» листьями салата [4]. Также для сортировки используются scara-роботы - небольшие четырехосевые машины, антропоморфные - шестиосевые промышленные механизмы, напоминающие по строению человеческую руку, и дельтароботы - скоростные системы с видеоуправлением для сортировки легких продуктов [3].

Что касается видеоуправления в процессах производства продукта питания, то последнее десятилетие «машинное» или «компьютерное зрение» стало применяться гораздо шире, единообразнее и более системно, что обусловлено постоянным развитием методологий, а именно обработки изображений и распознавания образов. Компьютерное зрение - технология, которая позволяет автоматизировать визуальной контроль и измерения, используя цифровые фотокамеры и методы анализа изображения.

Перспективы в данной области компьютерных технологий направлены на индивидуальные разработки в каждом элементе технологии, заключающиеся в создании обучаемых алгоритмов (например, гиперспектральная визуализация) [5].

Анализируя возможности роботизации производственного процесса изготовления пищи, так называемой «цифровой гастрономии», нельзя не отметить, что наиболее широкое распространение получили роботизированные измельчители и всевозможные смесители рецептурных ингредиентов. Итальянские инженеры создали роботов для выпечки печенья. Эти механизмы посредством управления компьютерной программы могут подобрать ингредиенты, смешать их в правильном порядке, и положить полученное тесто в противень духовки (рис.1) [6]. 


\section{Схема приготовления выпечки} посредством роботизации технологического процесса

Смеситель«виртуоз»

Цифровое управление

Роботизированный шеф-повар
Комбинирование и смешивание разнообразных ингредиентов при контроле их количества

в зависимости от типа источника Моделирование состава теста

в комбинации с моделью специфической формы определённого размера

Рис. 1. Схема технологического процесса приготовления выпечки

Необходимость индивидуализации продукта и привлечения потребителя посредством геометрической сложности дизайна продукта стала толчком для появления аддитивных (послойных) технологий, к которым относится трехмерная (3D) печать. Процесс заключается в создании сложных твердых форм посредством наслоения слоя за слоем с учетом фазовых переходов или химических реакций слоёв в зависимости от природы сырья. Трехмерное печатание позволяет создать продукт с новаторскими формой, размером, внутренней структурой и вкусом, персонализированной химической формулой $[7,8,9]$.

Аддитивное производство пищевого продукта осуществляется посредством промышленного пищевого принтера. Компания Stratasys (США), в настоящее время самая крупная компания производства данного оборудования, отмечает, что самым пластичным сырьём для 3D-печати считается смесь сахарной пудры и какао - составных частей шоколада [10]. Технологи пищевых производств достаточно широко адаптировали 
Плодоводство и виноградарство Юга России № 61(1), 2020 г.

трехмерную печать для получения продуктов питания из злаков (печенье, макароны, хлопья и т.д.), шоколада, различных спредов, обогащенных молочных, мясных и рыбных продуктов.

По мнению некоторых исследователей, мясопродукты, полученные при 3D-печати без использования добавок, станут серьёзным альтернативным источником протеина [11]. Плодово-ягодное сырье, являясь источником биологически ценных веществ, вместе с тем является технологически пригодным для технологии 3D-печати[8].

В зависимости от природы сырья целевого продукта применяют различные технологии «печатания». Технология струйной печати основана на применении блока пневматических сопл-двигателей мембраны, которая наслаивает слой на движущийся объект, посредством термических или пьезоэлектрических головок. В качестве материала используют: шоколад, жидкое тесто, сахарную глазурь, джемы, гели [12]. При порошковой печати различают три подтипа: селективное лазерное спекание, селективное спекание и плавление горячего воздуха при применении жидкости при общем порошковом напылении. При жидкостной печати применяют гидрофильные полимеры [12], камеди [13].

Методы 3D-печати влияют на свойства конечной конструкции пищевого продукта. Отмечено, что для данной технологии эффективен метод штранг-прессования (послойная экструзия) $[14,15,16]$. В основе современных исследований лежит выявление зависимости материалов, используемых в процессе штранг-прессования, от механизма размещения слоёв при контроле реологических свойств материалов; свойств затвердевания от параметров охлаждения, формирования гидрогеля.

Существует три различных экструзионных печати, применимые для печати пищевых продуктов: со смещением; с распределением давления во времени и винтовая [17]. Отмечается, что наиболее оптимальным является винтовой метод печати [18]. 
Для научного сообщества в области изучения аддитивных технологий перспективно изучение механизмов увеличения эффективности 3Dпечати в зависимости от используемого сырья. Для получения необходимой вязкости материала мягкой текстуры (теста, мясного фарша, плавленого сыра) используются различные гидрогели, как правило, это высокомолекулярные соединения, к которым относятся производные, в первую очередь, плодов и ягод, высоко- и низкоэтерефицированные пектиновые вещества. Также по мнению британских ученых, эффективны гидроколлоиды: ксантан и желатин, альгинаты, модифицированная целлюлоза [19].

В работе китайских учёных исследованы реологические и механические свойства гелей лимонного сока. При этом изучено влияние параметров печати на качество напечатанных продуктов с учетом высоты, диаметра сопла, параметров штранг-прессования и скорости движения сопла. Отмечено, что для печатания продукта на основе гелей лимонного сока диаметр сопла соответствовал 1 мм, выход профиля при штранг-прессовании $24 \mathrm{~mm}^{3} /$. Установлено, что оптимальная скорость перемещения сопла для печати 3D-конструкций - 30 мм/c. При данных параметрах продукт соответствовал целевой геометрии, обладал более гладкой текстурой поверхности и меньшим количеством точечных дефектов $[15,16]$.

В работе бельгийских ученых рассмотрена концепция биопечати [20]. Апробирован новый подход к использованию пищевых полиграфических биочернил на основе смеси вытяжки из клеток листьев салата и геля низкометоксилированного пектина с добавлением сыворотки с бычьим альбумином. Установлено, что механическая прочность увеличивается при концентрации пектина и уменьшается с увеличением воздушной фракции и концентрации инкапсулированных клеток.

Разработка полиграфических биочернил базируется на конфликтующих критериях: текучесть, выживаемость клетки и окончательная ригидность (устойчивость 3D-структуры). Методология, представленная в 
Плодоводство и виноградарство Юга России № 61(1), 2020 г.

настоящем исследовании, может рассматриваться как первый шаг для того чтобы произвести напечатанную 3D клеточную биопищу [20]. Говоря о персонификации форм и текстур пищевых продуктов, аддитивные технологии позволяют конструировать диетический продукт заданного состава (функциональный): содержание сахара/соли, биологически активных веществ. Китайские ученые совместно с австралийскими коллегами изучали питание пожилых людей, испытывающих трудности с жеванием и глотанием. Непривлекательная кашеобразная еда вызывала потерю аппетита, приводящую к недостатку питания.

Посредством 3D-печати учёными были созданы ньокки, имитирующие вкус и текстуру богатых незаменимыми аминокислотами бобов. Мягкая, протертая текстура, а также привлекательный вид позволили облегчить проглатывание [21].

Сложность принятия оптимальных решений, обеспечивающих стабильность качества создаваемого продукта и вместе с тем эффективность рационов и режимов питания, обусловливается вероятностным разбросом характеристик и свойств исходных компонентов биологического сырья, а также индивидуальностью физиологических особенностей организма [22]. Поэтому химический состав сырья и продуктов питания для человека является одним из важных каналов информации [1].

Информационные пищевые технологии в свою очередь связаны с математическими методами идентификации и прогнозирования качества продукта питания, так как позволяют скорректировать и оптимизировать специализированные рационы питания в рамках индивидуальных предпочтений и пищевой адекватности.

Для разработки функционального продукта могут быть использованы задачи рецептурной оптимизации с введением гибких рецептур, допускающих определенные изменения количественных соотношений между компонентами в зависимости от конкретно содержащихся в них элементов 
Плодоводство и виноградарство Юга России № 61(1), 2020 г.

химического состава. При этом постановка задачи связана с введением критериев минимизации отклонений от заданного или эталонного содержания групп показателей пищевой и биологической ценности, например заданного суточного минерального состава [23].

В каждом конкретном случае адекватные решения связаны с индивидуальным выбором и коррекцией состава рационов и продуктов питания согласно медико-биологическим требованиям, учитывающим параметры определённой группы людей, структурных соотношений и ограничений на компонентном, элементном и моно- структурном уровнях.

При конструировании многокомпонентного продукта следует:

1. Составить информационный банк данных, который должен включать вид, химический состав, оптовые цены ингредиентов и стандартный состав разрабатываемого продукта.

2. На основании банка данных составить балансовые уравнения по химическому составу продукта. Установить технологические ограничения (в соответствии с нормативными документами) на использование отдельных видов ингредиентов.

3. Определить функцию цели для проведения оптимизации рецептуры.

4. Решить поставленную задачу в компьютерной математической системе.

5. Проанализировать с технологической точки зрения варианты и выбрать рецептуру, которая отвечает поставленным целям.

Широкое распространение персональных компьютеров и использование систем компьютерной математики (MathCAD, Excel) позволяет творчески конструировать рецептуру поликомпонентных продуктов с заданными свойствами - минимальной себестоимостью и планируемой биологической и энергетической ценностью [24]. 
Как было отмечено, первым этапом конструирования пищевого продукта является создание информационного банка данных. Сотрудниками лаборатории хранения и переработки плодов и ягод ФГБНУ СКФНЦСВВ созданы и зарегистрированы в патентном ведомстве базы данных химических показателей качества плодов яблони летнего (32 сорта), осеннего (20 сортов), зимнего (233 сорта) сроков созревания; плодов черешни (98 сортов), вишни (59 сортов), сливы (68 сортов), персика (32 сорта) и абрикоса (42 сорта); ягод земляники (101 сорт), малины (52 сорта), смородины черной (20 сортов), смородины красной (26 сортов) и крыжовника (23 сорта), произрастающих в условиях юга России.

Базы данных включают технические (высота, диаметр, масса, твердость мякоти) и химические показатели качества плодов (сухие вещества, сахара, кислоты, витамин С, Р-активные вещества (прежде всего, катехины), полифенолы (общие полифенолы, флавонолы, лейкоантоцианы, антоцианы), $\beta$-каротин, пектин, минеральный состав (калий, кальций, магний)) в комплексе с климатическими данными зон произрастания [25, 26, 27].

Базы предназначены для накопления, оперативного поиска, хранения и анализа информации о химических показателях качества плодов; для селекционных работ при выделении сортов с высокими показателями качества; для целенаправленного управления технологическими процессами, позволяющими формировать товарные качества, пищевую ценность плодов и их лежкоспособность; обоснования целесообразности использования плодов различных сортов в технологических процессах при производстве консервной продукции (соки, варенье, компоты, джемы, сухофрукты, цукаты), дифференцировать сырье по критериальным показателям качества, как источника ингредиентов в технологии производства функциональных продуктов питания[25, 26, 27, 28].

На основе баз данных химических показателей качества плодов были созданы рецептуры сортовых функциональных консервов (табл. 1). 
Плодоводство и виноградарство Юга России № 61(1), 2020 г.

Таблица 1 - Химический состав консервов «Земляника в сиропе»

\begin{tabular}{|l|c|c|c|c|c|}
\hline \multirow{2}{*}{\multicolumn{1}{|c|}{ Сорт }} & \multicolumn{5}{c|}{ Содержание } \\
\cline { 2 - 6 } & РСВ & кислот & витамина С & витамина Р & антоцианов \\
\hline Моллинг Пандора & 10,2 & 0,38 & 49,7 & 32,5 & 36,7 \\
\hline Елизавета & 9,3 & 0,33 & 48,5 & 33,5 & 28,1 \\
\hline Аромас & 10,3 & 0,40 & 45,6 & 31,5 & 33,1 \\
\hline Флоренс & 9,5 & 0,45 & 48,2 & 31,1 & 31,2 \\
\hline Камароса & 9,7 & 0,37 & 44,5 & 31,1 & 36,3 \\
\hline Диамант & 9,3 & 0,45 & 46,0 & 33,4 & 34,9 \\
\hline
\end{tabular}

Сравнительно короткий технологический процесс производства позволяет сохранить питательные свойства ягод земляники В среднем в консервах «Земляника в сиропе» сохранилось до 70,0 \% витаминов С и Р и до 75,0 \% антоцианов. Рассмотрим принцип корректировки соотношения рецептурных ингредиентов в зависимости от их биологической ценности и термолабильности химических компонентов в процессе переработки посредством балансовых уравнений (табл. 2).

Наличие системы уравнений позволяет описывать изменения химического состава разрабатываемого многокомпонентного продукта в зависимости от соотношения и массовой доли используемых сырьевых компонентов. Это даёт возможность заменить дальнейшее исследование процесса формирования состава функциональных многокомпонентных консервов анализом математической модели согласно формуле:

$$
\mathrm{Y}=\mathrm{K} 1 \cdot \mathrm{X} 1+\mathrm{K} 2 \mathrm{X} 2+\mathrm{K} 3 \mathrm{X}_{3}+\ldots+\mathrm{K} \text {, }
$$

где - К1, К2, К3 Кп - процентное содержание вводимого компонента в композицию;

$\mathrm{X} 1, \mathrm{X} 2, \mathrm{X} 3, \quad$ Хп -содержание определённого компонента химического состава сырья и продукта. 
Таблица 2 - Математическое моделирование нового вида консервной продукции «Десерт землянично-ореховый»

\begin{tabular}{|c|c|c|}
\hline Сырьё & Рецептура, \% & Балансовое уравнение \\
\hline $\begin{array}{l}\text { Земляника протёртая, } \\
\text { сорт Елизавета (X1) }\end{array}$ & 74,0 & $\begin{array}{l}\text { Составлено по формуле: } \\
\mathrm{y}=\mathrm{X} 1 \mathrm{~B} 1+\mathrm{X} 2 \mathrm{~B} 2+\mathrm{X} 3 \mathrm{~B} 3+\mathrm{X} 4 \mathrm{~B} 4\end{array}$ \\
\hline $\begin{array}{l}\text { Орех грецкий молоч- } \\
\text { ной зрелости протёр- } \\
\text { тый, сорт Пелан (X2) }\end{array}$ & 1,5 & $\begin{array}{l}\text { где В1, В2, В3, В4, В5 - содер- } \\
\text { жание компонентов в сырье име- } \\
\text { ет вид: }\end{array}$ \\
\hline $\begin{array}{l}\text { Орех грецкий потре- } \\
\text { бительской зрелости, } \\
\text { сорт Дачный (X3) }\end{array}$ & 2,0 & $\begin{array}{l}\text { Для витамина С: } \\
0,48,5 \mathrm{X} 1+1,0 \mathrm{X} 2+12,3 \mathrm{X} 3+0,2 \mathrm{X} 4+ \\
0,03 \mathrm{X} 5=55,7 ;\end{array}$ \\
\hline $\begin{array}{l}\text { Порошок из яблочной } \\
\text { выжимки, Айдаред } \\
\text { (X3) }\end{array}$ & 2,5 & $\begin{array}{l}\text { Для витамина Р: } \\
0,35 \mathrm{X} 1+0,8 \mathrm{X} 2+0,9 \mathrm{X} 3+0,14 \mathrm{X} 4+ \\
0,12=70,5\end{array}$ \\
\hline $\begin{array}{l}\text { Сок концентрирован - } \\
\text { ный из брусники (X4) }\end{array}$ & 0,48 & Для полифенолов общих: \\
\hline Caxap & 19,5 & $\begin{array}{l}1,9 \times 1+1,15 \times 2+1,89 \times 3+2,74 X 4+ \\
2,1 \times 5=95,8\end{array}$ \\
\hline Лимонная кислота & 0,2 & $\begin{array}{l}\text { Для пектина: } 0,9 \mathrm{X} 1+5,5 \mathrm{X} 4+ \\
0,2 \mathrm{X} 5=1,0 ; \\
\text { Сумма природных } \\
\text { антиоксидантов } 237,7 \text { мг/100 г }\end{array}$ \\
\hline
\end{tabular}

Далее конструирование рецептур многокомпонентных продуктов питания осуществлялось посредством пакета программ «МаШса 2000». Имеющийся научный и методический способ получения продукта функционального назначения, даёт возможность получения продуктов питания более высокого уровня, учитывающих требования современной диетологии и медицины.

Заключение. Анализ литературных источников показывает, что внедрение цифровых технологий в производство продуктов питания из 
Плодоводство и виноградарство Юга России № 61(1), 2020 г.

растительного сырья является перспективным. Цифровизация пищевых технологий облегчает создание продукта заданного сбалансированного химического состава посредством создания компьютерных алгоритмов, в основе которого лежит оцифрованный результат научного исследования как самого пищевого ингредиента, так и механизмов технологического процесса получения продукта.

\section{Литература}

1. Еделев Д.А., Сидоренко Л.Ю., Перминова М.А. Нутригеномика как важный фактор при проектировании рациона питания человека // Пищевая промышленность.2011. № 4. С. 14-17.

2. Цифровая Россия: Новая реальность / А. Аптекман, В. Калабин, В. Клинцов [и др.]. // Москва: Мс Kinsey. Июль. 2017. С. 13-18.

3. Промышленные роботы в пищевой промышленности: пекари, кондитеры и резка ультразвуком, 03.03.2014. http://www.agbz.ru/articles/ promyishlennyie-robotyi-vpischevoy-promyishlennosti-pekari-konditeryi-i-rezka-ultrazvukom

4. Что делают роботы в пищевой промышленности, 11.08.2017. http://www.robogeek. ru/promyshlennye-roboty/chto-delayut-roboty-v-pischevoi-promyshlennosti

5. R. Lind, A. Murhed. Computer Vision Technology in the Food and Beverage Industries, 5 - Computer vision in food processing: an overview // Woodhead Publishing Series in Food Science, Technology and Nutrition.2012. Pages 133-149.

6. Jie Sun, Zhuo Peng, Weibiao Zhou, Jerry Y.H.Fuh, Geok Soon Hong, Annette Chiu. A Review on 3D Printing for Customized Food Fabrication // Procedia Manufacturing. 2015. Volume 1.Pages 308-319.

7. Большаков А. Пять технологий цифровой эры промышленности // CONTROLEN GINEERING POССИЯ 2017. № 6 (72). С. 15-25.

8. Ilde Ricci, Antonio Derossi, Carla Severini.Fundamental sof 3D Food Printing and Applications//Chapter 5 - 3D Printed Food From Fruitsand Vegetables. 2019. Pages 117-149.

9. Большаков А., Чеканова О. Наступила ли эпоха аддитивных технологий в отечественной промышленности? // Вектор высоких технологий. 2017. №1 (30). C. 11-15.

10. Jeffrey I. Lipton, Meredith Cutler, Franz Nigl, Dan Cohen, Hod Lipson. Additive manufacturing for the food industry // Trends in Food Science \& Technology. 2015. № 43. P. 114-123.

11. Stéphane Portanguen, Pascal Tournayre, Jason Sicard, Thierry Astruc, PierreSylvain Mirade. Toward the design of functional foods and biobased products by 3D printing: A review// Trends in Food Science \& Technology. 2019. № 86. P. 188-198.

12. Fernanda C. Godoi, Sangeeta Prakash, Bhesh R. Bhandari.3d printing technologies applied for food design: Status and prospects // Journal of Food Engineering. 2016. № 179. P. 44-54.

13. Hyun Woo Kim, Hojae Bae, Hyun Jin Park. Classification of the printability of selected food for 3D printing: Development of an assessment method using hydrocolloids as reference material // Journal of Food Engineering. 2017. № 215. P. 23-32. 
14. Valerie Vancauwenberghe, Mulugeta Admasu Delele, Jeroen Vanbiervliet, Wondwosen Aregawi, Pieter Verboven, Jeroen Lammertyn, Bart Nicolaï. Model-based design and validation of food texture of 3D printed pectin-based food stimulants // Journal of Food Engineering. 2018. № 231. P. 72-82.

15. FanliYang, Min Zhang, Bhesh Bhandari, Yaping Liu. Investigation on lemon juice gel as food material for 3D printing and optimization of printing parameters // LWT Food Science and Technology. 2018. № 87. P. 67-76.

16. Jie Sun, Weibiao Zhou, Liangkun Yan, Dejian Huang, Lien-ya Lin. Extrusionbased food printing for digitalized food design and nutrition control // Journal of Food Engineering. 2018. № 220. P.1-11.

17. Lee, J. M., Yeong, W. Y. A preliminary model of time-pressure dispensing system for bioprinting based on printing and material parameters: This paper reports a method to predict and control the width of hydrogel filament for bioprinting applications // Virtual and Physical Prototyping. 2015. № 10(1). P. 3-8.

18. Sylvester Mantihal, Sangeeta Prakash, Fernanda Condi Godoi, Bhesh Bhandari. Optimization of chocolate 3D printing by correlating thermal and flow properties with 3D structure modeling // Innovative Food Science and Emerging Technologies. 2017. № 44. P. 21-29.

19. Sonia Holland, Tim Foster, William MacNaughtan, Chris Tuck. Design and characterisation of food grade powders and inks for microstructure control using 3D printing // Journal of Food Engineering. 2018. № 220. P. 12-19.

20. Valerie Vancauwenberghe, Victor Baiye Mfortaw Mbong, ElsVanstreels, Pieter Verboven, Jeroen Lammertyn, Bart Nicolai. 3D printing of plant tissue for innovative food manufacturing: Encapsulation of alive plant cells into pectin based bio-ink // Journal of Food Engineering. 2017. XXX. P.1-11.

21. Zhenbin Liu, Min Zhang, Bhesh Bhandari, Yuchuan Wang.3D printing: Printing precision and application in food sector// Trends in Food Science \& Technology. 2017. № 69. P. 83-94.

22. Ивашкин Ю.А., Никитина М.А., Щур Д.А. Моделирование и оптимизация адекватного питания с учётом индивидуальных медико-биологических требований // Хранение и переработка сельхозсырья. 2007. № 2. С. 71-74.

23. Глазкова И.В., Ивашкин Ю.А. Оптимизация рационов питания с использованием компьютерных технологий // Пищевая промышленность. 2010. № 6. С. 61-63.

24. П.А. Лисин. Компьютерное моделирование поликомпонентных молочных продуктов // Пищевая промышленность. 2006. № 11. С. 60-61.

25. Свидетельство на базу данных №2012620962. База химических показателей качества плодов яблони летних, осенних, зимних сроков созревания, выращиваемых в условиях юга России / Причко Т.Г.; заявитель и правообладатель ФГБНУ СКФНЦСВВ; заявка № 2012620765; заявл. 20.07.2012; опубл. 19.09.2012.

26. Свидетельство на базу данных №2014620720. База биохимических, технических и технологических показателей качества плодов косточковых культур с учетом сортовых особенностей, выращенных в условиях юга России / Причко Т.Г.; заявитель и правообладатель ФГБНУ СКФНЦСВВ; заявка № 2014620321; заявл. 21.03.2014; опубл. 21.05.2014.

27. Свидетельство на базу данных №2015621027 База биохимических, технических и технологических показателей качества ягодных культур с учетом сортовых особенностей, выращенных в условиях юга России / Причко Т.Г.; заявитель и правообладатель ФГБНУ СКФНЦСВВ; заявка № 2015620515; заявл. 14.05.2015; опубл. 06.07. 2015. 
28. Новые виды консервной продукции функционального назначения из плодово-ягодного сырья / Т.Г. Причко, Л.Д. Чалая, М.В. Карпушина, М.Г. Германова, Т.Л. Смелик, Н.В. Дрофичева // Высокоточные технологии производства, хранения и переработки плодов и ягод: материалы межд. науч.-практ. конф.. Краснодар: СКЗНИИСиВ, 2010. С. 373-378.

\section{References}

1. Edelev D.A., Sidorenko L.Yu., Perminova M.A. Nutrigenomika kak vazhnyj faktor pri proektirovanii raciona pitaniya cheloveka // Pishchevaya promyshlennost'.2011. № 4. S. 14-17.

2. Cifrovaya Rossiya: Novaya real'nost' / Aptekman A., Kalabin V., Klincov V. [i dr.]. // Moskva: Mc Kinsey. Iyul'. 2017. S. 13-18.

3. Promyshlennye roboty $\mathrm{v}$ pishchevoj promyshlennosti: pekari, konditery i rezka ul'trazvukom, 03.03.2014. http://www.agbz.ru/articles/ promyishlennyie-robotyi-v-pischevoypromyishlennosti-pekari-konditeryi-i-rezka-ultrazvukom

4. Chto delayut roboty $\mathrm{v}$ pishchevoj promyshlennosti, 11.08.2017. http://www.robogeek. ru/promyshlennye-roboty/chto-delayut-roboty-v-pischevoi-promyshlennosti

5. R. Lind, A. Murhed. Computer Vision Technology in the Food and Beverage Industries, 5 - Computer vision in food processing: an over-view // Woodhead Publishing Series in Food Science, Technology and Nutri-tion.2012. Pages 133-149.

6. Jie Sun, Zhuo Peng, Weibiao Zhou, Jerry Y.H. Fuh, Geok Soon Hong, Annette Chiu. A Review on 3D Printing for Customized Food Fabrication // Procedia Manufacturing.2015. Volume 1. Pages 308-319.

7. Bol'shakov A. Pyat' tekhnologij cifrovoj ery promyshlennosti // CONTROLEN GINEERING ROSSIYa 2017. №6 (72). S. 15-25.

8. Ilde Ricci, Antonio Derossi, Carla Severini.Fundamental sof 3D Food Printing and Applications//Chapter 5 - 3D Printed Food From Fruitsand Vegetables.2019. Pages 117-149.

9. Bol'shakov A., Chekanova O. Nastupila li epoha additivnyh tekhnologij v otechestvennoj promyshlennosti? // Vektor vysokih tekhnologij. 2017. №1 (30). S. 11-15.

10. Jeffrey I. Lipton, Meredith Cutler, Franz Nigl, Dan Cohen, Hod Lipson. Additive manufacturing for the food industry // Trends in Food Science \& Technology. 2015. № 43. P. 114-123.

11. Stéphane Portanguen, Pascal Tournayre, Jason Sicard, Thierry Astruc, PierreSylvain Mirade. Toward the design of functional foods and biobased products by 3D printing: A review// Trends in Food Science \& Technology. 2019. № 86. P. 188-198.

12. Fernanda C. Godoi, Sangeeta Prakash, Bhesh R. Bhandari.3d printing technologies applied for food design: Status and prospects // Journal of Food Engineering. 2016. № 179. P. 44-54.

13. Hyun Woo Kim, Hojae Bae, Hyun Jin Park. Classification of the printability of selected food for 3D printing: Development of an assessment method using hydrocolloids as reference material // Journal of Food Engineering. 2017. № 215. P. 23-32.

14. Valerie Vancauwenberghe, Mulugeta Admasu Delele, Jeroen Vanbiervliet, Wondwosen Aregawi, Pieter Verboven, Jeroen Lammertyn, Bart Nicolaï. Model-based design and validation of food texture of 3D printed pectin-based food stimulants // Journal of Food Engineering. 2018. № 231. P. 72-82.

15. FanliYang, Min Zhang, Vhesh Bhandari, Yaping Liu. Investiga-tion on lemon juice gel as food material for 3D printing and optimization of printing parameters // LWT Food Science and Technology. 2018. № 87. P. 67-76. 
16. Jie Sun, Weibiao Zhou, Liangkun Yan, Dejian Huang, Lien-ya Lin. Extrusionbased food printing for digitalized food design and nutrition control // Journal of Food Engineering. 2018. № 220. P. 1-11.

17. Lee, J. M., Yeong, W. Y. A preliminary model of time-pressure dispensing system for bioprinting based on printing and material parameters: This paper reports a method to predict and control the width of hydrogel filament for bioprinting applications // Virtual and Physical Prototyping. 2015. №1 0(1). P. 3-8.

18. Sylvester Mantihal, Sangeeta Prakash, Fernanda Condi Godoi, Bhesh Bhandari. Optimization of chocolate 3D printing by correlating thermal and flow properties with 3D structure modeling // Innovative Food Science and Emerging Technologies. 2017. № 44. P. 21-29.

19. Sonia Holland, Tim Foster, William MacNaughtan, Chris Tuck. Design and characterisation of food grade powders and inks for microstructure control using 3D printing // Journal of Food Engineering. 2018. №220. P. 12-19.

20. Valerie Vancauwenberghe, Victor Baiye Mfortaw Mbong, ElsVanstreels, Pieter Verboven, Jeroen Lammertyn, Bart Nicolai. 3D printing of plant tissue for innovative food manufacturing: Encapsulation of alive plant cells into pectin based bio-ink // Journal of Food Engineering. 2017.HHH. P.1-11.

21. Zhenbin Liu, Min Zhang, Bhesh Bhandari, Yuchuan Wang.3D printing: Printing precision and application in food sector// Trends in Food Science \& Technology. 2017. № 69. P. 83-94.

22. Ivashkin Yu.A., Nikitina M.A., Shchur D.A. Modelirovanie i optimizaciya adekvatnogo pitaniya s uchetom individual'nyh mediko-biologicheskih trebovanij // Hranenie i pererabotka sel'hozsyr'ya. 2007. № 2. S. 71-74.

23. Glazkova I.V., Ivashkin Yu.A. Optimizaciya racionov pitaniya s ispol'zovaniem komp'yuternyh tekhnologij // Pishchevaya promyshlennost'. 2010. № 6. S. 61-63.

24. P.A. Lisin. Komp'yuternoe modelirovanie polikomponentnyh molochnyh produktov // Pishchevaya promyshlennost'. 2006. № 11. S. 60-61.

25. Svidetel'stvo na bazu dannyh №2012620962. Baza himicheskih pokazatelej kachestva plodov yabloni letnih, osennih, zimnih srokov sozrevaniya, vyrashchivaemyh v usloviyah yuga Rossii / Prichko T.G.; zayavitel' i pravoobladatel' FGBNU SKFNCSVV; zayavka № 2012620765; zayavl. 20.07.2012; opubl. 19.09.2012.

26. Svidetel'stvo na bazu dannyh №2014620720. Baza biohimicheskih, tekhnicheskih i tekhnologicheskih pokazatelej kachestva plodov kostochkovyh kul'tur s uchetom sortovyh osobennostej, vyrashchennyh v usloviyah yuga Rossii / Prichko T.G.; zayavitel' i pravoobladatel' FGBNU SKFNCSVV; zayavka № 2014620321; zayavl. 21.03.2014; opubl. 21.05.2014.

27. Svidetel'stvo na bazu dannyh №2015621027 Baza biohimicheskih, tekhnicheskih i tekhnologicheskih pokazatelej kachestva yagodnyh kul'tur s uchetom sortovyh osobennostej, vyrashchennyh $\mathrm{v}$ usloviyah yuga Rossii / Prichko T.G.; zayavitel' i pravoobladatel' FGBNU SKFNCSVV; zayavka № 2015620515; zayavl. 14.05.2015; opubl. 06.07. 2015.

28. Novye vidy konservnoj produkcii funkcional'nogo naznacheniya iz plodovoyagodnogo syr'ya / T.G. Prichko, L.D. Chalaya, M.V. Karpushina, M.G. Germanova, T.L. Smelik, N.V. Droficheva // Vysokotochnye tekhnologii proizvodstva, hraneniya i pererabotki plodov i yagod: materialy mezhdunarodnoj nauchno-prakticheskoj konferencii. Krasnodar: SKZNIISiV, 2010. S. 373-378. 